\title{
Validation of FORMOSAT-7/COSMIC2 IVM ion density and TGRS orbit electron density
}

\author{
Min-Yang Chou ${ }^{1, *}$, John J. Braun ${ }^{1}$, Qian $\mathrm{Wu}^{1,2}$, Roderick A. Heelis ${ }^{3}$, Irina Zakharenkova ${ }^{1}$, Iurii Cherniak ${ }^{1}$, \\ Nicholas M. Pedatella ${ }^{1,2}$, and Russell A. Stoneback ${ }^{3}$ \\ ${ }^{1}$ COSMIC Program Office, University Corporation for Atmospheric Research, Boulder, CO, USA \\ ${ }^{2}$ High Altitude Observatory, National Center for Atmospheric Research, Boulder, CO, USA \\ ${ }^{3}$ University of Texas at Dallas, Dallas, TX, USA
}

\begin{abstract}
Article history:
Received 29 April 2021

Revised 18 June 2021

Accepted 22 June 2021

Keywords:

FORMOSAT-7/COSMIC2, IVM ion

density, TGRS orbit electron density

Citation:

Chou, M.-Y., J. J. Braun, Q. Wu, R. A Heelis, I. Zakharenkova, I. Cherniak, N. M. Pedatella, and R. A. Stoneback, 2021: Validation of FORMOSAT-7/ COSMIC2 IVM ion density and TGRS orbit electron density. Terr. Atmos. Ocean. Sci., 32, 939-951, doi: 10.3319/TAO.2021.06.22.01
\end{abstract}

\begin{abstract}
In this study, the comparison between the orbit electron density and total ion density measured by payloads of Tri-GNSS Radio-Occultation System (TGRS) and Ion Velocity Meter (IVM) onboard the FORMOSAT-7/COMSIC2 (F7/C2) satellites is presented. The collocated TGRS and IVM observations for each of the F7/C2 satellites at $\sim 715$ and $\sim 540 \mathrm{~km}$ are evaluated during the whole year of 2020. Comparative analysis reveals that the TGRS and IVM density observations have high correlation coefficients of $0.92-0.96$ for each of the $\mathrm{F} 7 / \mathrm{C} 2$ satellites. The mean differences are around $-0.03 \times 10^{4}$ to $0.02 \times 10^{4} \mathrm{~cm}^{-3}$ with standard deviations ranging from $\sim 0.91$ $\times 10^{4}$ to $2.18 \times 10^{4} \mathrm{~cm}^{-3}$, demonstrating a good agreement between the independent TGRS and IVM observations. Furthermore, the collocated observations are utilized to examine the global spatial and temporal variations of the topside ionosphere. The results show that the morphologies of the topside ionosphere in TGRS orbit electron density are nearly identical to the IVM ion density, suggesting that both $\mathrm{F} 7 / \mathrm{C} 2$ payloads reliably produce accurate topside ionosphere observations. We found that the TGRS orbit electron density tends to be $10-30 \%$ smaller than the IVM ion density in the daytime equatorial ionosphere region at both high and low orbits, but the density differences decrease to approximately -30 - $0 \%$ during the nighttime. These density differences could be due to the error caused by the spherical symmetry assumption in TGRS orbit electron density estimation. Observing system simulation experiments are further performed to evaluate the relative errors between the TGRS and IVM density observations at high and low orbits.
\end{abstract}

\section{INTRODUCTION}

The Global Navigation Satellite Systems (GNSS) radio occultation (RO) limb-sounding technique is a powerful technique for the global sounding of the atmosphere and ionosphere. In 2006, the FORMOSAT-3/COSMIC (F3/C) mission, a joint Taiwan and the United States RO satellite mission, was launched from Vandenberg Air Force Base, California. The F3/C mission created the first RO constellation for meteorology, ionosphere, and climate. This constellation consisted of six LEO satellites at orbits of $72^{\circ}$ inclination at $\sim 800 \mathrm{~km}$ altitude, providing real-time global atmospheric and ionospheric data for research and opera-

\footnotetext{
* Corresponding author

E-mail:mingyan0211@gmail.com
}

tional use (e.g., Cheng et al. 2006; Schreiner et al. 2007; Anthes et al. 2008). Over its mission lifetime, the F3/C constellation has improved the capability of weather prediction, climate monitoring, and space weather forecast with unprecedented accuracy (e.g., Scherliess et al. 2009; Anthes 2011; Yue et al. 2012; Matsuo et al. 2013; Hsu et al. 2014, 2018; Lin et al. 2017; Sun et al. 2017; Ho et al. 2020), as well as advanced the understanding of the ionosphere variability (Lin et al. 2007, 2009, 2010, 2012; Burns et al. 2008; Zeng et al. 2008; Liu et al. 2010; Pedatella et al. 2011, 2014; Zakharenkova et al. 2012, 2017; Chang et al. 2013a, b, 2015, 2020; Pedatella and Maute 2015; Wu et al. 2017).

The success of the F3/C mission motivated the followon mission FORMOSAT-7/COSMIC2 (F7/C2), which 
similarly collects atmosphere and ionosphere data using the RO technique (Anthes and Schreiner 2019; Fong et al. 2019; Schreiner et al. 2020). The F7/C2 constellation, consisting of six LEO satellites, was launched on 25 June 2019 into six evenly spaced circular orbits of $24^{\circ}$ inclination to be ultimately deployed at $\sim 540 \mathrm{~km}$ altitude, providing unprecedented data coverage within $\pm 45^{\circ}$ in latitude. The new F7/C2 constellation is equipped with next-generation GNSS receivers, so-called Tri-GNSS RO System (TGRS), developed by National Aeronautics and Space Administration's Jet Propulsion Laboratory (Tien et al. 2012), which can track GPS and GLONASS signals with higher signal-to-noise ratio, improving the quality of the RO measurements. With upgrades to flight software, the TGRS may be able to track Galileo signals as well. TGRS not only measures the temperature, moisture, and pressure in the atmosphere, it also provides measurements of total electron content (TEC) and electron density in the ionosphere. $\mathrm{F} 7 / \mathrm{C} 2$ provides more than 4000 neutral atmosphere RO profiles per day, with nearly 6000 ionosphere tracks per day. In addition to the TGRS, each F7/C2 satellite has an Ion Velocity Meter (IVM, Heelis et al. 2017) and the Radio Frequency Beacon (RFB) science payload providing dense ionospheric sampling $\pm 24^{\circ}$ of the equator. The IVM measures in situ ion density, temperature, and drift velocity. The RFB enables measurements of TEC and ionospheric scintillation by ground-based receivers. These scientific payloads provide high-quality data that will contribute to terrestrial and space weather forecasts and ionosphere research (e.g., Chou et al. 2020; Ho et al. 2020; Lin et al. 2020a, b; Wu 2020; Chen et al. 2021; Cherniak et al. 2021; Rajesh et al. 2021).

The topside ionospheric measurements are considered a valuable database for ionosphere and space weather research (e.g., Gentile et al. 2006; Heelis et al. 2009) and for improvement of empirical and operational ionospheric models (e.g., Bilitza et al. 2017). Validating the topside ionosphere measurements is therefore crucial to evaluate scientific satellite payloads' performance (e.g., Hajj and Romans 1998; Jakowski et al. 2002). Lei et al. (2007) showed that the F3/C RO electron density agrees well with the Incoherent Scatter Radars (ISR) electron density in the topside ionosphere, demonstrating that the F3/C RO limb-sounding technique provides accurate measurements. A similar study using F7/C2 electron density by Cherniak et al. (2021) showed similar high-quality comparisons between ISR observations and RO derived electron density profiles. Yue et al. (2011) compared the orbit electron density measured by the CHAllenging Minisatellite Payload (CHAMP) RO with the in-situ Planar Langmuir Probe (PLP) electron density. Comparison between the PLP and RO observations showed that the RO orbit electron density tends to be greater than the PLP electron density by $\sim 10 \%$. They suggested that the discrepancy between the RO and PLP measurements might be due to the assumption of spherical symmetry in the RO orbit electron density retrieval (Syndergaard et al. 2006). However, the errors in PLP electron density are unknown, and may also contribute to the density difference. Lai et al. (2013) and Pedatella et al. (2015) compared the F3/C RO electron density with the collocated in-situ observations from CHAMP and Communications/Navigation Outage Forecasting System. These studies show overall good agreement between the RO and in-situ satellite observations. Their results also revealed a systematic error in the equatorial and low-latitude daytime ionosphere due to the usage of the Abel inversion to retrieve the $\mathrm{RO}$ electron density profiles.

Although the studies mentioned above suggest that the topside ionosphere measurements from the RO and in-situ satellite observations should have high accuracy, it remains a challenge to evaluate the accuracy of in-situ satellite observations with the RO density observations on the spatial and temporal basis due to the limited number of collocated observations. This study aims to validate the F7/C2 IVM ion density with the TGRS orbit electron density. Both TGRS and IVM payloads onboard the F7/C2 satellites provide a unique opportunity for validation with abundant collocated observations. We compare the IVM ion density with the TGRS orbit electron density for each of the F7/C2 satellites to investigate the data quality and the error distribution in terms of local time, magnetic latitude, month, and orbit altitude throughout the year 2020. Since the assumptions of circular orbit and constant electron density along the orbit track (i.e., spherical symmetry assumption) could lead to systematic errors in TGRS electron density retrieval (Syndergaard et al. 2006; Yue et al. 2010), observation system simulation experiments (OSSEs) are, therefore, performed to estimate the relative errors between the TGRS and IVM density that are due to retrieval errors.

\section{DATA}

\subsection{F7/C2 TGRS Orbit Electron Density}

The F7/C2 TGRS orbit electron density can be obtained in the level 2 ionPrf files (variable name: edorb) in the CDAAC database. The CDAAC F7/C2 TGRS electron density profiles are derived using the Abel inversion through the TEC observations (e.g., Lei et al. 2007). In order to derive the orbit electron density, the F7/C2 TECs are calibrated to obtain the portion of TEC below the LEO satellites by subtracting the non-occultation side TEC from the occultation side TEC (e.g., Schreiner et al. 1999; Yue et al. 2011). Under the assumptions of spherical symmetry and straight-line propagation, the relation between the calibrated TEC $\left(T E C_{\text {cal }}\right)$ and electron density $\left(N_{e}\right)$ can be expressed through the Abel transform (Schreiner et al. 1999):

$T E C_{c a l}\left(r_{0}\right)=2 \int_{r_{0}}^{r_{o r b}} \frac{r N_{e}(r)}{\sqrt{r^{2}-r_{0}^{2}}} d r$ 
where $r_{\text {orb }}$ and $r_{0}$ are the radius of the satellite orbit and the distance from the Earth's center to the tangent point. The electron density profile can be calculated recursively from top to bottom along with the tangent points. A first-order estimate of orbit electron density $N_{e}\left(r_{\text {orb }}\right)$ can be obtained by solving Eq. (1). The solution of Eq. (1) can be expressed as follows:

$$
\begin{aligned}
T E C_{c a l}\left(r_{0}\right) & =2 N_{e}\left(r_{o r b}\right) \sqrt{r_{o r b}^{2}-r_{0}^{2}} \\
& \approx 2 N_{e}\left(r_{o r b}\right) \sqrt{2 r_{o r b}\left(r_{o r b}-r_{0}\right)}
\end{aligned}
$$

The orbit electron density is essentially calculated by fitting a square root function of $T E C_{c a l}\left(r_{0}\right)$ for the uppermost few kilometers $(\sim 10 \mathrm{~km})$ with the assumptions of constant electron density and a circular orbit (Syndergaard et al. 2006).

\subsection{F7/C2 IVM Ion Density}

The IVM is developed by the University of Texas at Dallas and has been successfully utilized on many satellite missions such as Dynamic Explorer, the Defense Meteorological Satellite Program (DMSP), ROCSAT, and the Ionospheric Connections Explorer (ICON). The IVM consists of two planar thermal ion sensors, a Retarding Potential Analyzer (RPA) and an Ion Drift Meter (IDM). The RPA measures the energy of plasma along the direction of satellite motion, and the IDM measures the arrival angle of plasma. Both sensors are utilized to derive currents and voltages for calculating the total ion density, composition, temperature, and drift through a least-square fitting procedure (Heelis et al. 2017). Wu et al. (2022) proposed a differential TGRS slant TEC method to derive $N_{e}\left(r_{o r b}\right)$ and provide a linear correction to the IVM ion densities. This method is similar to Syndergaard et al. (2006), but the two methods are slightly different. Wu et al. (2022) set a rigorous criterion to derive $N_{e}\left(r_{\text {orb }}\right)$ by limiting the boresight angle between the LEO and GNSS to be 0.5 degrees, which indicates that the F7/C2 satellite velocity (or anti-velocity) vector aligns with the direction of the GNSS satellite. The distance (ds) traveled by the F7/C2 satellites is settled on a 2-second separation between two slant TEC samples, approximately $15 \mathrm{~km}$ in the horizontal distance. Under such conditions, 9 pairs of slant TEC samples are available to derive 9 density values $\left(N_{e}=d T E C /\right.$ $d s)$, which are then averaged to obtain a single $N_{e}\left(r_{\text {orb }}\right)$. The derived $N_{e}\left(r_{\text {orb }}\right)$ has high precision of less than $5 \%$. The linear coefficients between the slant TEC-derived $N_{e}\left(r_{o r b}\right)$ and IVM ion density are further estimated through a leastsquare fitting and applied to remove the bias of the IVM ion density (https://data.cosmic.ucar.edu/gnss-ro/cosmic2/nrt/ F7C2 SpWx IVM Density Data Release Memo.pdf). This method can estimate $N_{e}\left(r_{o r b}\right)$ more accurately without using Eq. (2), which requires assumptions of constant electron density and a circular orbit, though limited data are available due to the constraint on the boresight angle. The corrected IVM ion density can be obtained in the level 2 ivmLv2 file (variable name: ion_dens) in the COSMIC Data Analysis and Archive Center (CDAAC, http://cdaac-www. cosmic.ucar.edu) database. Note that the original IVM ion density can also be obtained in the ivmLv2 file (variable name: orig_ion_density). This study uses the corrected IVM ion density with $1 \mathrm{~Hz}$ cadence to compare the F7/C2 TGRS orbit electron density.

\section{OBSERVATIONS}

At launch, all F7/C2 satellites were placed into an initial $\sim 700-720 \mathrm{~km}$ circular orbit. Satellites were lowered separately and allowed to precess away from the other satellites to achieve uniform observational coverage at low latitudes. Figure 1 shows the average orbit altitudes for each of the F7/C2 satellites in 2020. It shows that FM1 and FM4 are below $550 \mathrm{~km}$ orbits, and FM6 is $\sim 715 \mathrm{~km}$ orbit throughout the year. FM2, FM3, and FM5 were lowered to $\sim 540 \mathrm{~km}$ orbits from 700 - $720 \mathrm{~km}$ orbits in March, June, and September, respectively. Hence the F7/C2 observations during day-of-year (DOY) 001-365, 2020 provide an ideal period to validate the IVM and TGRS density observations at both low and high orbits. To mitigate spatial and temporal variations in observations, we restrict TGRS electron density and IVM ion density to samples that occur within $100 \mathrm{~km}$ and 1 -second. The comparison includes all latitudes, longitudes, and local times to obtain sufficient collocated observations from January to December 2020. Outliers greater than $1 \times$ $10^{6} \mathrm{~cm}^{-3}$ or smaller than $-2 \times 10^{5} \mathrm{~cm}^{-3}$ in TGRS electron density, approximately accounting for $0.0026 \%$ of total collocated observations (19/731052), are excluded. The total selected collocated observation number $(\mathrm{N})$ is 731052 .

Figure 2 shows the comparison between the TGRS orbit electron density and the IVM total ion density for each of the six F7/C2 satellites (named hereafter C2E1-C2E6). The TGRS orbit electron densities are generally consistent with the IVM ion density observations with correlation coefficients of $0.94,0.95,0.95,0.95,0.96$, and 0.92 for $\mathrm{C} 2 \mathrm{E} 1$ C2E6, respectively. We note that TGRS orbit electron densities show occasional negative values, accounting for $\sim 0.57 \%$ of the collocated observations. This indicates that the method used to estimate the orbit electron density [Eq. (2)] has degraded performance during some RO events (Syndergaard et al. 2004, 2006). Figure 3 shows the corresponding histograms of the difference between the collocated TGRS electron and IVM ion density observations (Ne-Ni). The mean density differences for each of the satellites are around -2.53 $\times 10^{3}$ to $0.31 \times 10^{3} \mathrm{~cm}^{-3}$ with standard deviations ranging from $\sim 0.91 \times 10^{4}$ to $2.08 \times 10^{4} \mathrm{~cm}^{-3}$. The density differences are relatively small compared to the average ion and orbit electron densities of $\sim 2.5 \times 10^{4}$ to $5.8 \times 10^{4} \mathrm{~cm}^{-3}$. Overall, the small mean differences and standard deviations demonstrate 


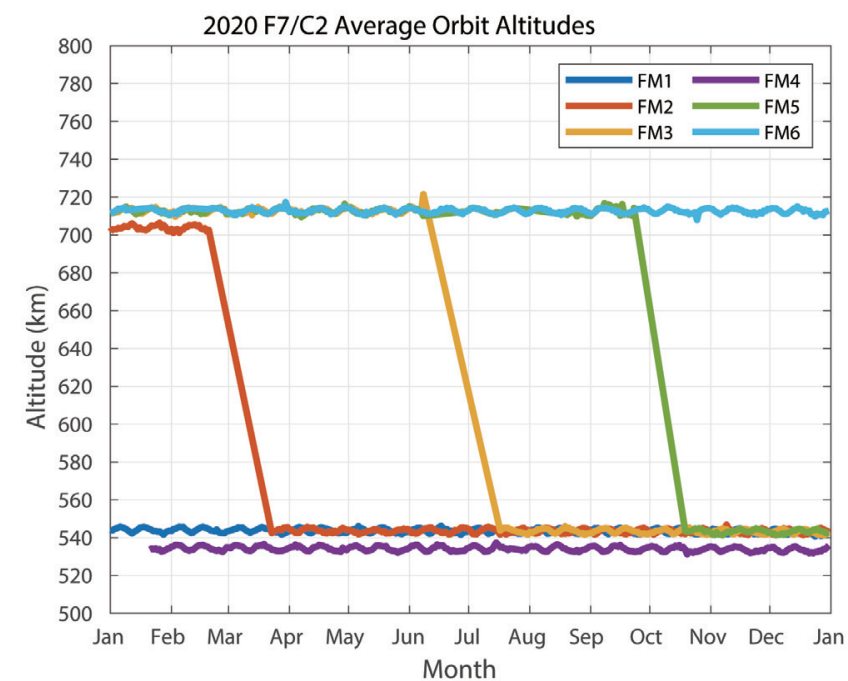

Fig. 1. The variation of average orbit altitudes for six F7/C2 satellites (C2E1-C2E6) in 2020.
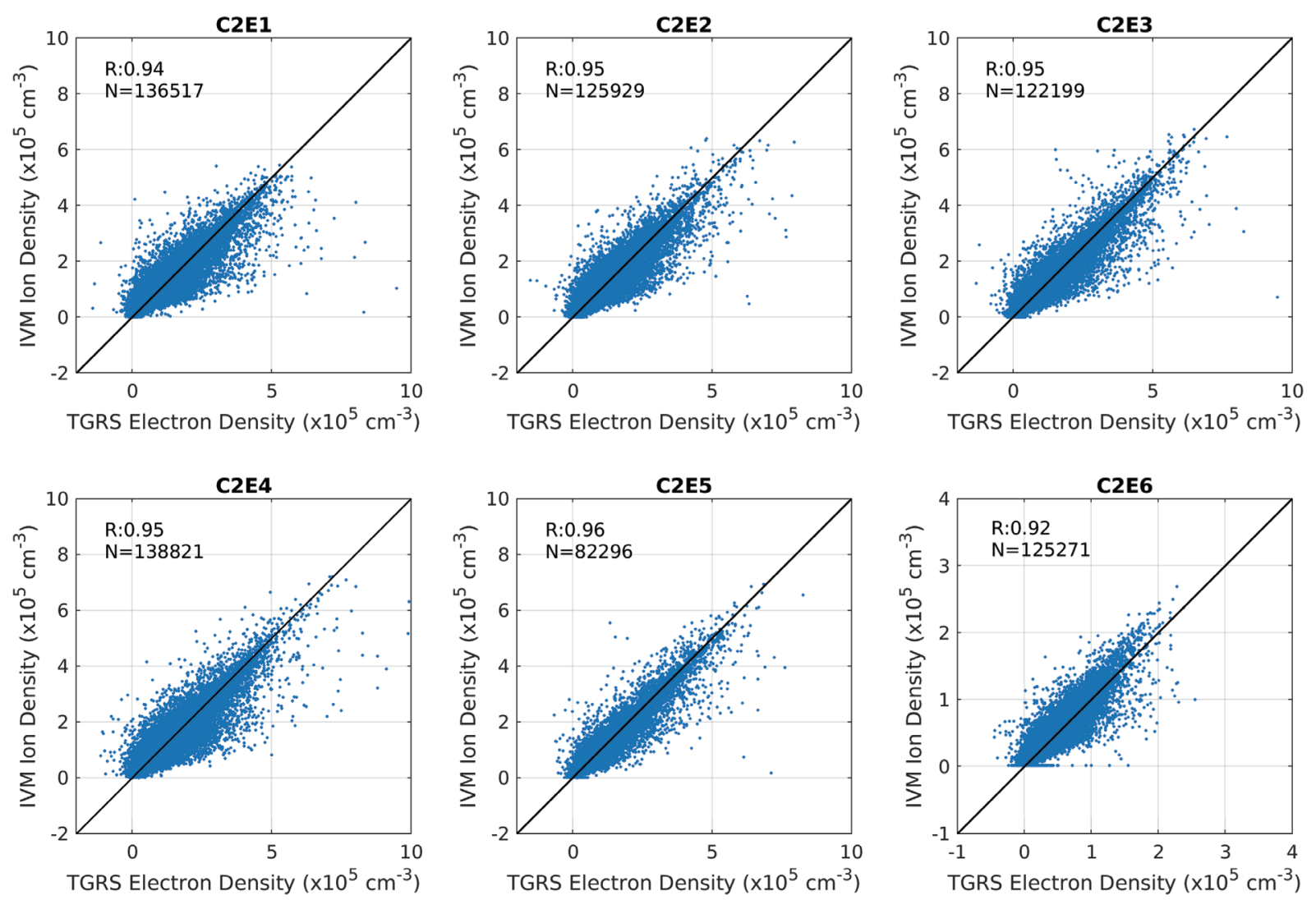

Fig. 2. Comparison between the TGRS electron density and IVM ion density for six F7/C2 satellites (C2E1-C2E6). 

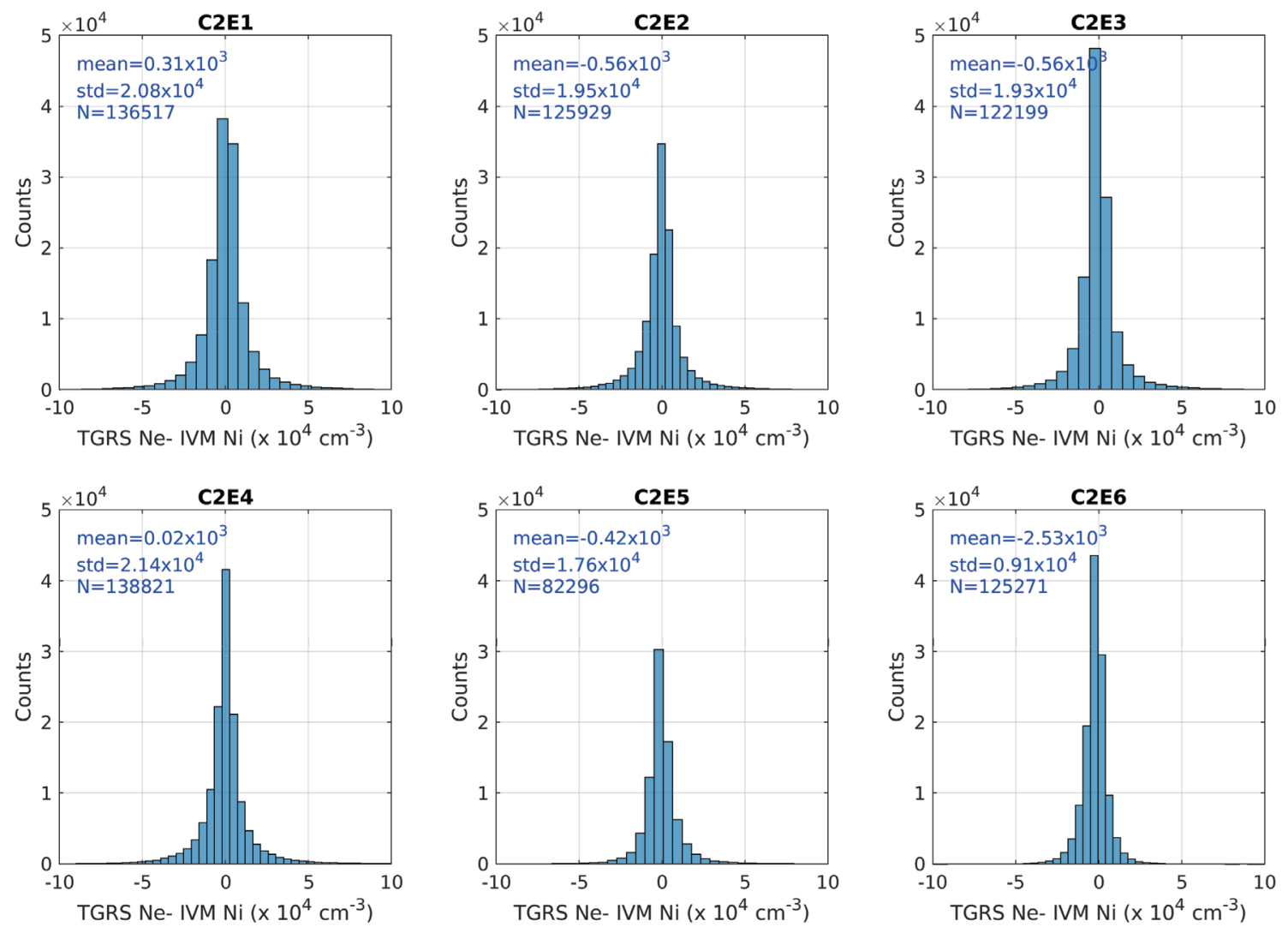

Fig. 3. Histograms of the difference between the TGRS electron density and IVM ion density for six F7/C2 satellites (C2E1-C2E6).

a good agreement between the TGRS and IVM observations.

To further examine the spatial and temporal variations of TGRS electron density and IVM totally ion density, the collocated observations are utilized to plot the density distribution as a function of magnetic local time (MLT) and magnetic latitude (MLAT) from January to December in 2020. These density maps are constructed by binning these two quantities into $0.5 \mathrm{~h} \times 2.5^{\circ} \mathrm{MLT} \times$ MLAT grids and taking the mean values in each grid-point. A three-grid smoothing window is then applied. Figures 4 and 5 show the TGRS orbit electron density (odd rows) and IVM ion density (even rows) maps for C2E1-C2E3 and C2E4-C2E6, respectively. The most prominent feature, the so-called equatorial-ionization anomaly (EIA) in the low latitude daytime ionosphere, can be identified in both observations. The EIA structures display significant semi-annual variations and hemispheric asymmetry, consistent with previous studies (e.g., Rishbeth et al. 2000; Tulasi Ram et al. 2009; Qian et al. 2013). Of particular significance is that the morphology of EIA structures in TGRS orbit electron density are nearly identical to the IVM ion density maps, implying that both TGRS and IVM payloads reliably produce accurate observations of the total topside ionospheric plasma density.

Note that the electron and ion density maps show significant differences between each of the satellites and/or months due to the altitudinal difference of satellite orbits as shown in Fig. 1. For example, C2E3 was at $710 \mathrm{~km}$ altitude from January to May and lowered to $\sim 540 \mathrm{~km}$ altitude from June to July, leading to a large difference in electron and ion densities between the first and second half of the year. The deployment phases of F7/C2 also lead to a significant gap in observations. Overall, the quantities of electron and ion densities between each of the F7/C2 satellites are similar when comparing the densities at a similar orbit altitude. However, the morphologies of EIA are slightly different because all longitudes have been selected to obtain global mean MLTMLAT density maps, which in turn result in discrepancies between each of the F7/C2 observations.

Figures 6 and 7 show the maps of density difference $(\mathrm{Ne}-\mathrm{Ni})$ and relative error $[(\mathrm{Ne}-\mathrm{Ni}) / \mathrm{Ni} \times 100 \%]$ as a function of MLAT and MLT. At lower orbit ( $\sim 540 \mathrm{~km})$, the error maps indicated by red triangles show significant decreases of about $0.5 \times 10^{4}$ to $2.5 \times 10^{4} \mathrm{~cm}^{-3}$, approximately -20 to $-10 \%$ of relative errors, in TGRS electron density around the daytime EIA region ( 08:00 - 18:00 LT). The density differences become smaller than $-1 \times 10^{4} \mathrm{~cm}^{-3}$ during 18:00 - 08:00 LT, but the relative errors increase to -30 to $-10 \%$ due to small background electron and ion densities. The error maps also show that the TGRS electron density tends to be greater than the IVM ion density by $10-20 \%$ 

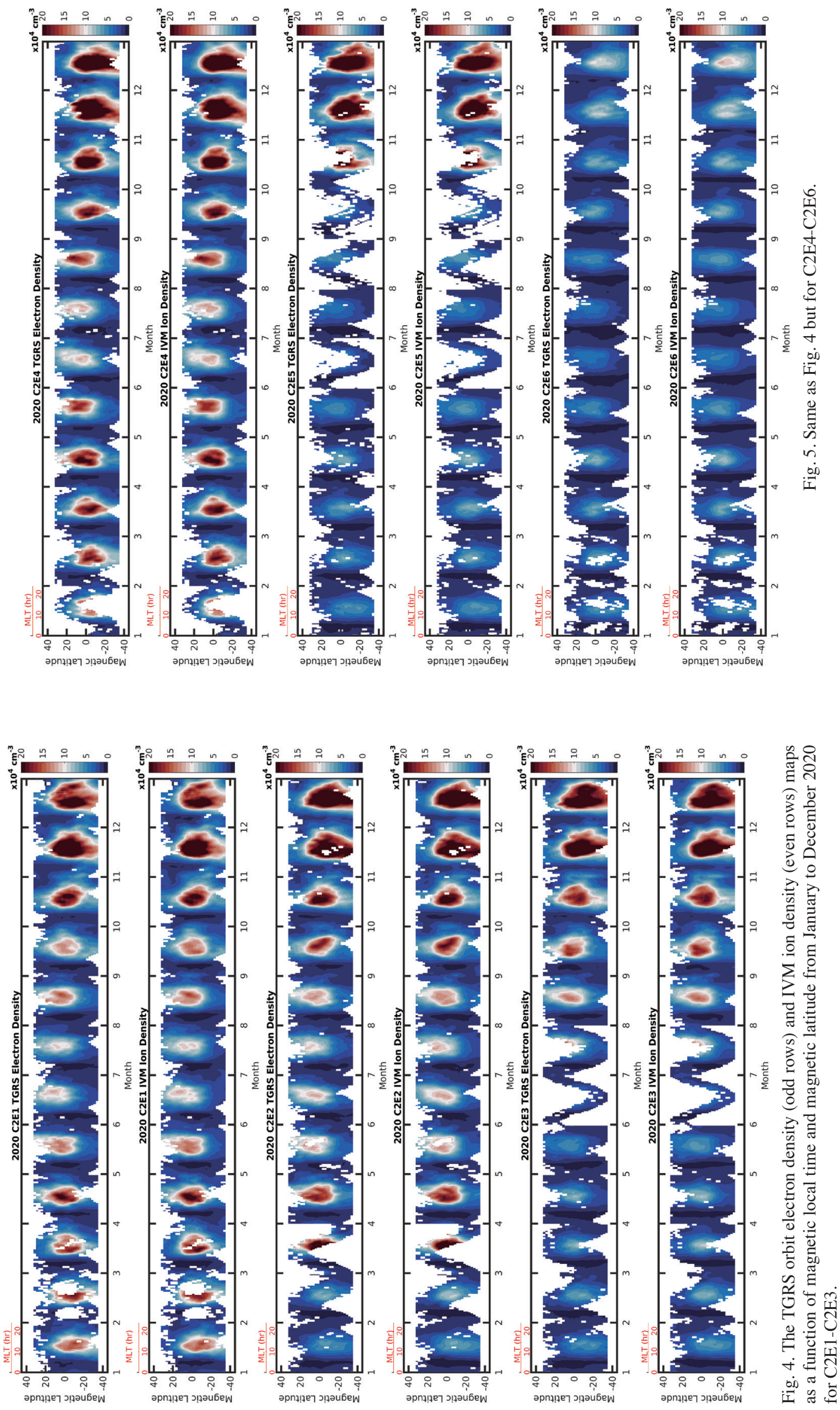

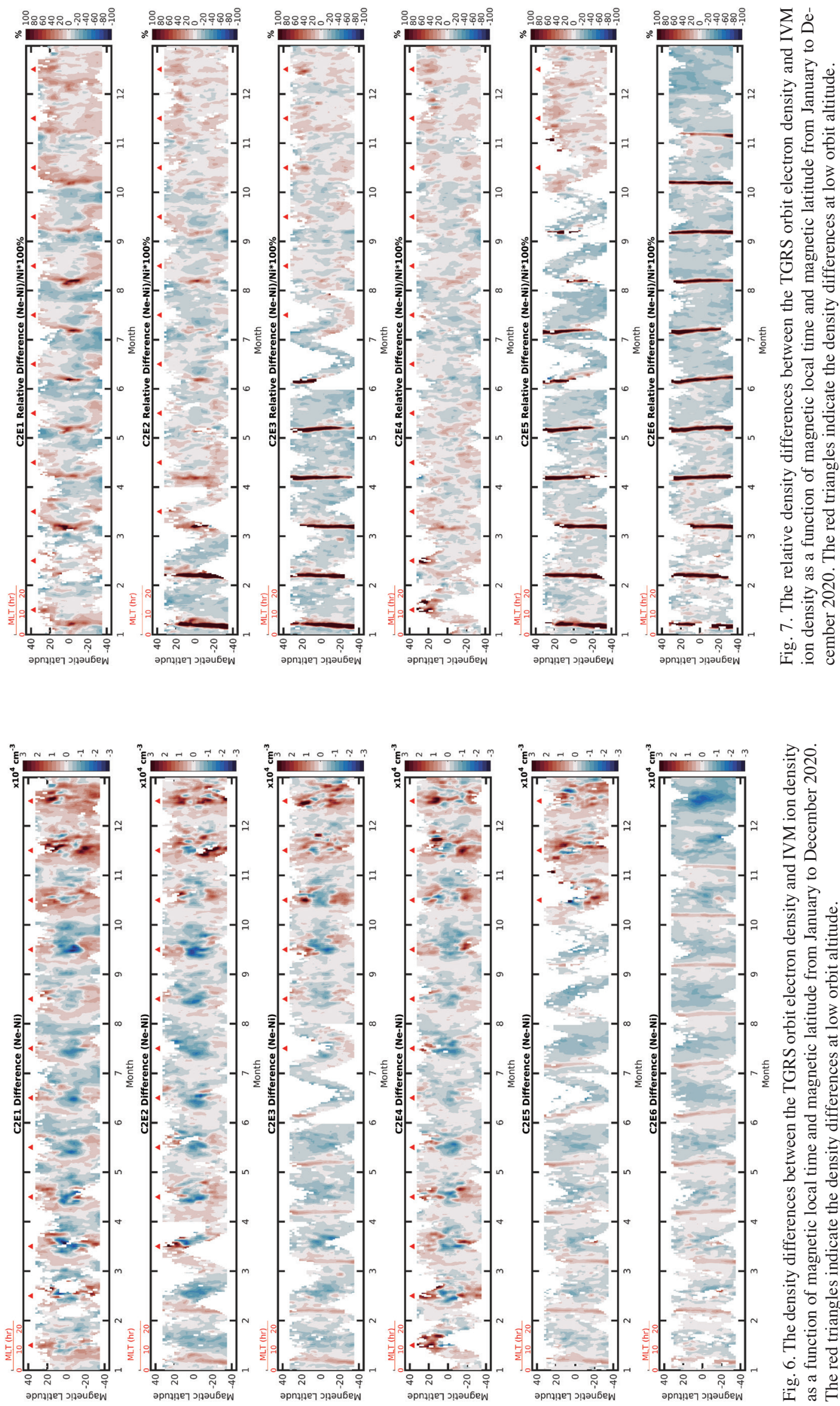

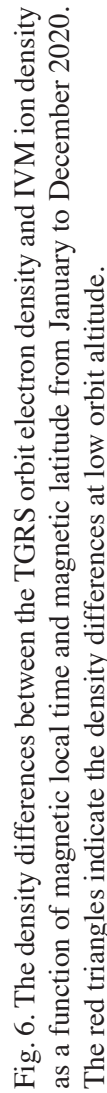


around the negative error EIA regions during the daytime. The decrease and increase in TGRS electron density around the EIA region could be due to the constant electron density assumption (i.e., spherical symmetry assumption) of Eq. (2), which is similar to the alternating bands of negative and positive errors due to the spherical symmetry assumption of the Abel inversion in the bottomside ionosphere (e.g., Pedatella et al. 2015).

At higher orbit $(\sim 715 \mathrm{~km})$, the error maps show a smaller decrease of about $-0.5 \times 10^{4}$ to $-1 \times 10^{4} \mathrm{~cm}^{-3}$, approximately -30 to $-10 \%$ of relative errors, in TGRS electron density around the daytime EIA region ( 08:00 - 18:00 LT). The density differences are nearly zero bias with relative errors of about -20 to $0 \%$ at $\sim 18: 00-08: 00 \mathrm{LT}$. We note that the relative errors can reach over 100\% at 04:00 LT when the background density reaches a minimum at both orbit altitudes. The IVM measurements have degradation when the total ion density is smaller than $3 \times 10^{4} \mathrm{~cm}^{-3}$ due to the much lower $\mathrm{O}^{+}$concentrations after midnight during the prevailing solar minimum conditions (e.g., Coley et al. 2010). Overall, the TGRS orbit electron density tends to be smaller than the IVM ion density in the EIA region. The density differences are greater at lower orbit than at higher orbit, which could be attributed to TGRS orbit electron density retrieval errors. More significant RO retrieval errors occur around the EIA region, as well as regions around dawn/dusk terminators where the horizontal gradients are prominent.

\section{OBSERVING SYSTEM SIMULATION EXPERIMENTS}

Although the TGRS orbit electron density and IVM ion density generally show a good agreement, it is a challenge to evaluate the accuracy of IVM ion density since the TGRS orbit electron density has systematic errors due to the spherical symmetry assumption. Therefore, observing system simulation experiments (OSSEs) are performed to assess the systematic errors in TGRS orbit electron density observations (e.g., Liu et al. 2015; Chou et al. 2017). Yue et al. (2011) indicated that the solar activity would not influence the relative Abel errors of electron density. It is expected that the relative error distributions of the OSSEs and the F7/ C2 observations should be comparable if the IVM ion density is accurate. Here the realistic RO line-of-sight (LOS) geometries between F7/C2 and GNSS satellites are utilized to simulate the synthetic RO TECs by inserting the LOS geometries into an empirical model ionosphere given by the International Reference Ionosphere (IRI) 2016 (Bilitza et al. 2017) with spatial and temporal resolutions of $1^{\circ} \times 1^{\circ} \times 5 \mathrm{~km}$ $\times 1 \mathrm{~h}$. We limit the altitudinal extension of the background IRI ionosphere up to $1000 \mathrm{~km}$ to reduce the computational cost. The impact of plasmaspheric TEC above $1000 \mathrm{~km}$ on ionospheric electron density retrieval is minor and negligible because only TEC below the orbit is utilized and the quantity of plasmaspheric TEC is small. The F7/C2 C2E1 and C2E6 RO LOS geometries during September 2020 are utilized to obtain sufficient spatial and temporal coverages and evaluate the errors at $\sim 540$ and $\sim 715 \mathrm{~km}$ orbit altitudes, respectively. We further calculate the synthetic $T E C_{c a l}$, and the synthetic orbit electron density can be estimated using Eq. (2) by fitting a square root function of $T E C_{c a l}\left(r_{0}\right)$ for the uppermost $\sim 10 \mathrm{~km}$ (Syndergaard et al. 2006). The systematic errors in OSSE orbit electron density, therefore, can be evaluated by comparing the OSSE orbit electron density with the OSSE truth (i.e., IRI ion density).

Figure 8 shows the OSSE truth ion density, OSSE orbit electron density, density difference $(\mathrm{Ne}-\mathrm{Ni})$, and relative difference $[(\mathrm{Ne}-\mathrm{Ni}) / \mathrm{Ni} \times 100 \%]$ maps as a function of magnetic latitude and local time at $\sim 540 \mathrm{~km}$ (left column) and $\sim 715 \mathrm{~km}$ (right column) orbit altitudes. At low orbit altitude, the density differences range from $-1 \times 10^{4}$ to -2.5 $\times 10^{4} \mathrm{~cm}^{-3}$ around the EIA region and are nearly zero after midnight. The relative differences are about $\pm 10 \%$. At high orbit altitude, the density differences range from $-0.5 \times 10^{4}$ to $-1.5 \times 10^{4} \mathrm{~cm}^{-3}$ around the EIA region and are nearly zero bias after midnight. The relative errors are about -30 to $0 \%$. The OSSE results reveal that the RO retrieved orbit electron density tends to be smaller than the truth ion density in the daytime EIA region and is nearly the same during the nighttime at both orbit altitudes. The density differences around the EIA region at high orbit are smaller than those at low orbit, which is consistent with the F7/C2 observations (Figs. 6 and 7). Significant errors in the EIA region are visible because the spherical symmetry assumption fails to account for the regions where the horizontal gradients are large and prominent. Additionally, the calibration error in $T E C_{\text {cal }}$ due to the same LEO-GNSS plane assumption and the uncertainty of least-square fitting of $T E C_{c a l}$ may also lead to errors in orbit electron density estimation. The error caused by the same LEO-GNSS plane assumption will be investigated in the future.

Figure 9 shows the histograms of relative differences for the OSSEs and F7/C2 observations at high and low orbits. It is noteworthy that the $\mathrm{F} 7 / \mathrm{C} 2$ errors exceeding $100 \%$ due to decreased IVM sensitivity in low density environments after midnight are excluded in the histogram to better represent the average and standard deviation. We found that the average OSSE errors tend to be smaller than the F7/ $\mathrm{C} 2$ observations by $\sim 5 \%$, implying that the F7/C2 IVM ion density may be underestimated by $\sim 5 \%$ at both orbit altitudes. However, the OSSE truth, which is based on the IRI empirical model, shows a wider latitudinal extension of the EIA, indicating that the F7/C2 could include more positive errors due to the actual EIA being narrower compared to the IRI-simulated one. This may affect the spatial error distribution and mean value. Overall, the OSSE histograms show that the systematic errors are around $-8.27 \pm 18.5 \%$ and 0.21 $\pm 17.41 \%$ at $\sim 715$ and $\sim 540 \mathrm{~km}$ altitudes. These quantities 

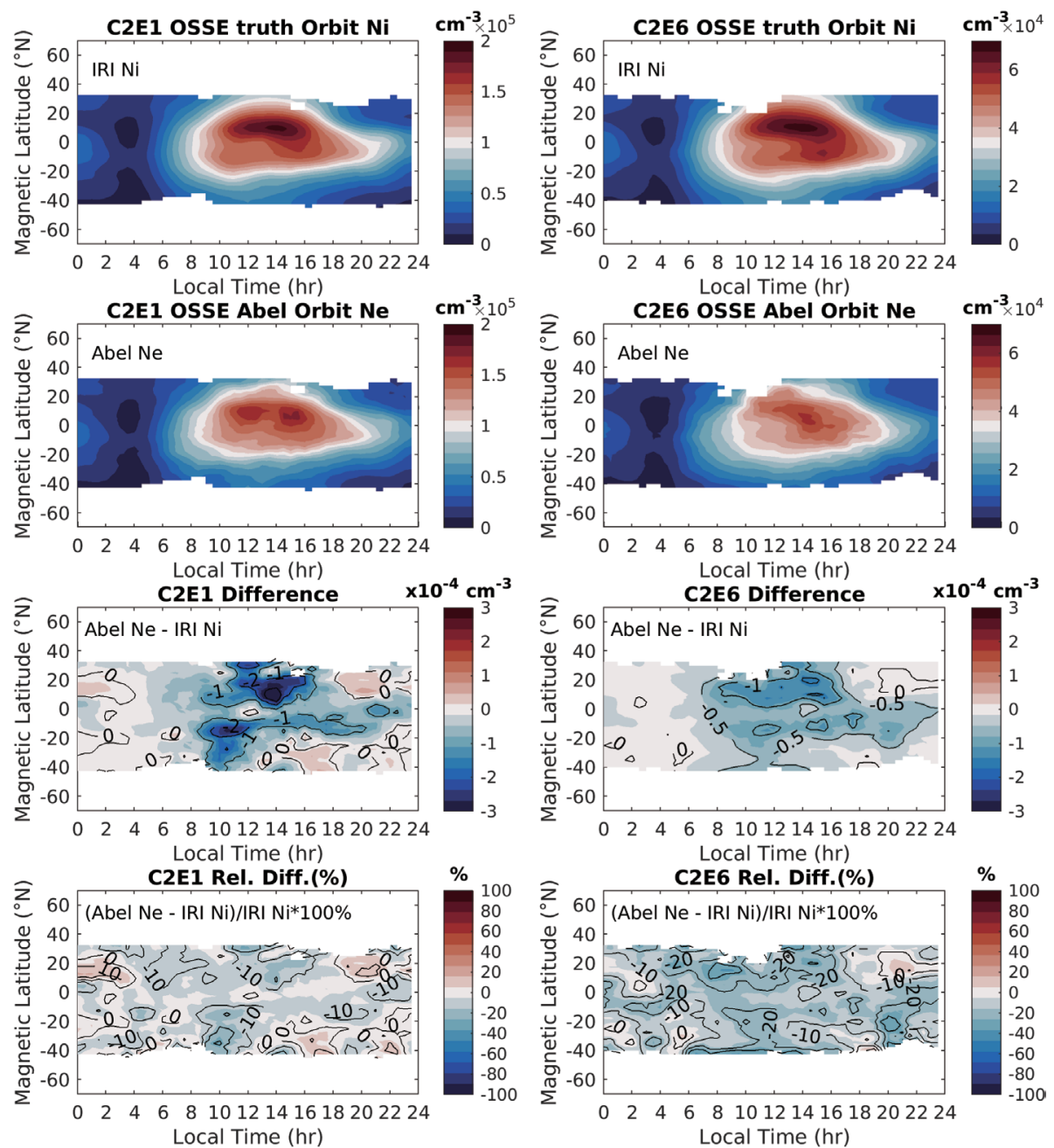

Fig. 8. The OSSE results of true ion density (top row), OSSE orbit electron density (second row), difference (third row), and relative difference (bottom row) at low (left column) and hight orbits (right column).
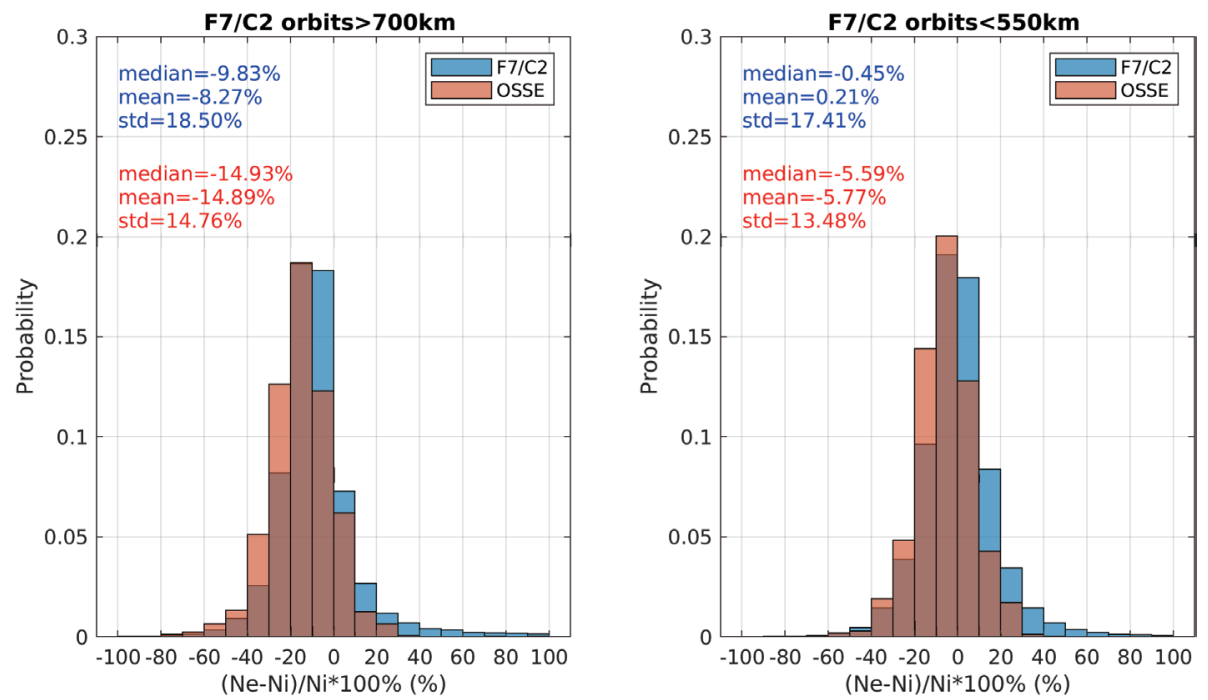

Fig. 9. Histograms of the relative density differences for OSSEs and F7/C2 at high (left) and low (right) orbits. 
are comparable to the $\mathrm{F} 7 / \mathrm{C} 2$ relative error distributions of about $-14.89 \pm 14.76 \%$ and $-5.77 \pm 13.48 \%$. Observations and simulations allow us to conclude that the F7/C2 IVM ion density should be accurate and reliable.

\section{CONCLUSIONS}

In this study, we compare the F7/C2 IVM total ion density with the collocated TGRS orbit electron density for six F7/C2 satellites at orbit altitudes of $\sim 540$ and $715 \mathrm{~km}$ throughout the year 2020. Both IVM and TGRS payloads onboard the F7/C satellites provide unprecedented collocated observations for mutual validations. The comparison shows that the TGRS orbit electron densities are consistent with the IVM ion density with high correlation coefficients of $0.92-0.96$. The mean density differences for each of the satellites are around $-0.03 \times 10^{4}$ to $0.02 \times 10^{4} \mathrm{~cm}^{-3}$ with standard deviations ranging from $\sim 0.91 \times 10^{4}$ to $2.18 \times 10^{4} \mathrm{~cm}^{-}$ ${ }^{3}$, demonstrating a good agreement between the TGRS and IVM observations. We also examine the spatial and temporal variations of TGRS and IVM density observations. The morphologies of EIA in both TGRS and IVM density observations are found to be nearly identical. However, significant density differences occur around the daytime EIA region. The TGRS electron density tends to be smaller than the IVM ion density by $\sim 0.5 \times 10^{4}$ to $2.5 \times 10^{4} \mathrm{~cm}^{-3}$ and $0.5 \times 10^{4}$ to $1 \times 10^{4}$ at low and high orbits. The density differences are within $-1 \times 10^{4} \mathrm{~cm}^{-3}$ or nearly zero between $\sim$ 18:00 - 08:00 LT at low and high orbit altitudes. We suggest that the spherical symmetric assumption used in TGRS orbit electron density estimation could lead to significant errors in the daytime EIA region and lower orbits where the horizontal gradients are relatively large and prominent. The IVM ion density also has significant degradation when the background densities reach a minimum after midnight ( 04:00 LT). Additionally, by comparing the error distributions of OSSEs with the F7/C2 results, our results reveal that the systematic errors in OSSEs are comparable to the errors in the $\mathrm{F} 7 / \mathrm{C} 2$ observations, indicating that the differences between F7/C2 orbit electron densities and IVM ion densities are primarily due to errors in the retrieval of the orbit electron density. We therefore conclude that the F7/ C2 IVM ion density should be accurate and reliable for the topside ionosphere research.

Acknowledgements This research is supported by National Science Foundation grant AGS-1522830 and United States Space Force contract FA8803-19-C-0004. This material is based upon work supported by the National Center for Atmospheric Research, which is a major facility sponsored by the National Science Foundation under Cooperative Agreement No. 1852977. The FORMOSAT-7/COSMIC2 data can be obtained from the COSMIC Data Analysis and Archive Center (CDAAC, http://cdaac-www.cosmic.ucar.edu)

\section{REFERENCES}

Anthes, R. A., 2011: Exploring Earth's atmosphere with radio occultation: Contributions to weather, climate and space weather. Atmos. Meas. Tech., 4, 1077-1103, doi: 10.5194/amt-4-1077-2011. [Link]

Anthes, R. A. and W. Schreiner, 2019: Six new satellites watch the atmosphere over Earth's equator. Eos, 100, doi: 10.1029/2019EO131779. [Link]

Anthes, R. A., P. A Bernhardt, Y. Chen, L. Cucurull, K. F. Dymond, D. Ector, S. B. Healy, S.-P. Ho, D. C Hunt, Y.-H. Kuo, H. Liu, K. Manning, C. McCormick, T. K. Meehan, W J. Randel, C. Rocken, W S. Schreiner, S. V. Sokolovskiy, S. Syndergaard, D. C. Thompson, K. E. Trenberth, T.-K. Wee, N. L. Yen, and Z Zeng, 2008: The COSMIC/FORMOSAT-3 mission: Early results. Bull.Amer. Meteorol.Soc., 89, 313-334, doi: 10.1175/ BAMS-89-3-313. [Link]

Bilitza, D., D. Altadill, V. Truhlik, V. Shubin, I. Galkin, B. Reinisch, and X. Huang, 2017: International Reference Ionosphere 2016: From ionospheric climate to realtime weather predictions. Space Weather, 15, 418-429, doi: 10.1002/2016SW001593. [Link]

Burns, A. G., Z. Zeng, W. Wang, J. Lei, S. C. Solomon, A. D. Richmond, T. L. Killeen, and Y.-H. Kuo, 2008: Behavior of the $F_{2}$ peak ionosphere over the South Pacific at dusk during quiet summer conditions from COSMIC data. J. Geophys. Res., 113, A12305, doi: 10.1029/2008JA013308. [Link]

Chang, F. Y., J. Y. Liu, T. W. Fang, P. K. Rajesh, and C. H. Lin, 2020: Plasma depletion bays in the equatorial ionosphere observed by FORMOSAT-3/COSMIC during 2007-2014. J. Geophys. Res., 125, e2019JA027501, doi: 10.1029/2019JA027501. [Link]

Chang, L. C., C.-H. Lin, J. Yue, J.-Y. Liu, and J.-T. Lin, 2013a: Stationary planetary wave and nonmigrating tidal signatures in ionospheric wave 3 and wave 4 variations in 2007-2011 FORMOSAT-3/COSMIC observations. J. Geophys. Res., 118, 6651-6665, doi: 10.1002/jgra.50583. [Link]

Chang, L. C., C.-H. Lin, J.-Y. Liu, N. Balan, J. Yue, and J.-T. Lin, 2013b: Seasonal and local time variation of ionospheric migrating tides in 2007-2011 FORMOSAT-3/COSMIC and TIE-GCM total electron content. J. Geophys. Res., 118, 2545-2564, doi: 10.1002/ jgra.50268. [Link]

Chang, L. C., H. Liu, Y. Miyoshi, C.-H. Chen, F.-Y. Chang, C.-H. Lin, J.-Y. Liu, and Y.-Y. Sun, 2015: Structure and origins of the Weddell Sea Anomaly from tidal and planetary wave signatures in FORMOSAT-3/COSMIC observations and GAIA GCM simulations. J. Geophys. Res., 120, 1325-1340, doi: 10.1002/2014JA020752. [Link]

Chen, S.-P., C. C. H. Lin, P. K. Rajesh, J.-Y. Liu, R. Eastes, 
M.-Y.Chou, and J.-M. Choi, 2021: Near real-time global plasma irregularity monitoring by FORMOSAT-7/ COSMIC-2. J. Geophys. Res., 126, e2020JA028339, doi: 10.1029/2020JA028339. [Link]

Cheng, C.-Z. F., Y.-H. Kuo, R. A. Anthes, and L. Wu, 2006: Satellite constellation monitors global and space weather. Eos, Trans. AGU, 87, 166, doi: 10.1029/2006EO170003. [Link]

Cherniak, I., I. Zakharenkova, J. Braun, Q. Wu, N. Pedatella, W. Schreiner, J.-P. Weiss, and D. Hunt, 2021: Accuracy assessment of the quiet-time ionospheric F2 peak parameters as derived from COSMIC-2 multi-GNSS radio occultation measurements. J. Space Weather Space Clim., 11, 18, doi: 10.1051/swsc/2020080. [Link]

Chou, M.-Y., C. C. H. Lin, H. F. Tsai, and C. Y. Lin, 2017: Ionospheric electron density inversion for Global Navigation Satellite Systems radio occultation using aided Abel inversions. J. Geophys. Res., 122, 1386-1399, doi: 10.1002/2016JA023027. [Link]

Chou, M.-Y., N. M. Pedatella, Q. Wu, J. D. Huba, C. C. H. Lin, W. S. Schreiner, J. J. Braun, R. W. Eastes, and J. Yue, 2020: Observation and simulation of the development of equatorial plasma bubbles: Post-sunset rise or upwelling growth? J. Geophys. Res., 125, e2020JA028544, doi: 10.1029/2020JA028544. [Link]

Coley, W. R., R. A. Heelis, M. R. Hairston, G. D. Earle, M. D. Perdue, R. A. Power, L. L. Harmon, B. J. Holt, and C. R. Lippincott, 2010: Ion temperature and density relationships measured by CINDI from the C/NOFS spacecraft during solar minimum. J. Geophys. Res., 115, A02313, doi: 10.1029/2009JA014665. [Link]

Fong, C.-J., C.-H. Chu, C.-L. Lin, and A. d. S. Curiel, 2019: Toward the Most Accurate Thermometer in Space: FORMOSAT-7/COSMIC-2 Constellation. IEEE Aerosp. Electron. Syst. Mag., 34, 12-20, doi: 10.1109/ MAES.2019.2924133. [Link]

Gentile, L. C., W. J. Burke, and F. J. Rich, 2006: A global climatology for equatorial plasma bubbles in the topside ionosphere. Ann. Geophys., 24, 163-172, doi: 10.5194/angeo-24-163-2006. [Link]

Hajj, G. A. and L. J. Romans, 1998: Ionospheric electron density profiles obtained with the global positioning system: Results from the GPS/MET experiment. Radio Sci., 33, 175-190, doi: 10.1029/97RS03183. [Link]

Heelis, R. A., W. R. Coley, A. G. Burrell, M. R. Hairston, G. D. Earle, M. D. Perdue, R. A. Power, L. L. Harmon, B. J. Holt, and C. R. Lippincott, 2009: Behavior of the $\mathrm{O}+/ \mathrm{H}+$ transition height during the extreme solar minimum of 2008. Geophys. Res. Lett., 36, L00C03, doi: 10.1029/2009GL038652. [Link]

Heelis, R. A., R. A. Stoneback, M. D. Perdue, M. D. Depew, W. A. Morgan, M. W. Mankey, C. R. Lippincott, L. L. Harmon, and B. J. Holt, 2017: Ion velocity measurements for the ionospheric connections explorer.
Space Sci. Rev., 212, 615-629, doi: 10.1007/s11214017-0383-3. [Link]

Ho, S.-P., X. Zhou, X. Shao, B. Zhang, L. Adhikari, S. Kireev, Y. He, J. G. Yoe, W. Xia-Serafino, and E. Lynch, 2020: Initial Assessment of the COSMIC-2/ FORMOSAT-7 Neutral Atmosphere Data Quality in NESDIS/STAR Using In Situ and Satellite Data. Remote Sens., 12, 4099, doi: 10.3390/rs12244099. [Link]

Hsu, C.-T., T. Matsuo, W. Wang, and J.-Y. Liu, 2014: Effects of inferring unobserved thermospheric and ionospheric state variables by using an Ensemble Kalman Filter on global ionospheric specification and forecasting. J. Geophys. Res., 119, 9256-9267, doi: 10.1002/2014JA020390. [Link]

Hsu, C.-T., T. Matsuo, and J.-Y. Liu, 2018: Impact of assimilating the FORMOSAT-3/COSMIC and FORMOSAT-7/COSMIC-2 RO data on the midlatitude and low-latitude ionospheric specification. Earth Space Sci., 5, 875-890, doi: 10.1029/2018EA000447. [Link]

Jakowski, N., A. Wehrenpfennig, S. Heise, C. Reigber, H. Lühr, L. Grunwaldt, and T. K. Meehan, 2002: GPS radio occultation measurements of the ionosphere from CHAMP: Early results. Geophys. Res. Lett., 29, 95-195-4, doi: 10.1029/2001GL014364. [Link]

Lai, P.-C., W.J. Burke, and L.C. Gentile, 2013: Topside electron density profiles observed at low latitudes by COSMIC and compared with in situ ion densities measured by C/NOFS. J. Geophys. Res., 118, 2670-2680, doi: 10.1002/jgra.50287. [Link]

Lei, J., S. Syndergaard, A. G. Burns, S. C. Solomon, W. Wang, Z. Zeng, R. G. Roble, Q. Wu, Y.-H. Kuo, J. M. Holt, S.-R. Zhang, D. L. Hysell, F. S. Rodrigues, and C. H. Lin, 2007: Comparison of COSMIC ionospheric measurements with ground-based observations and model predictions: Preliminary results. J. Geophys. Res., 112, A07308, doi: 10.1029/2006JA012240. [Link]

Liu, J. Y., C. Y. Lin, C. H. Lin, H. F. Tsai, S. C. Solomon, Y. Y. Sun, I. T. Lee, W. S. Schreiner, and Y. H. Kuo, 2010: Artificial plasma cave in the low-latitude ionosphere results from the radio occultation inversion of the FORMOSAT-3/COSMIC. J. Geophys. Res., 115, A07319, doi: 10.1029/2009JA015079. [Link]

Liu, J. Y., C. Y. Lin, and H. F. Tsai, 2015: Electron density profiles probed by radio occultation of FORMOSAT-7/COSMIC-2 at 520 and $800 \mathrm{~km}$ altitude. Atmos. Meas. Tech., 8, 3069-3074, doi: 10.5194/amt-8-30692015. [Link]

Lin, C. H., J. Y. Liu, T. W. Fang, P. Y. Chang, H. F. Tsai, C. H. Chen, and C. C. Hsiao, 2007: Motions of the equatorial ionization anomaly crests imaged by FORMOSAT-3/COSMIC. Geophys. Res. Lett., 34, L19101, doi: 10.1029/2007GL030741. [Link]

Lin, C. H., J. Y. Liu, C. Z. Cheng, C. H. Chen, C. H. Liu, 
W. Wang, A. G. Burns, and J. Lei, 2009: Three-dimensional ionospheric electron density structure of the Weddell Sea Anomaly. J. Geophys. Res., 114, A02312, doi: 10.1029/2008JA013455. [Link]

Lin, C. H., C. H. Liu, J. Y. Liu, C. H. Chen, A. G. Burns, and W. Wang, 2010: Midlatitude summer nighttime anomaly of the ionospheric electron density observed by FORMOSAT-3/COSMIC. J. Geophys. Res., 115, A03308, doi: 10.1029/2009JA014084. [Link]

Lin, C. Y., T. Matsuo, J. Y. Liu, C. H. Lin, J. D. Huba, H. F. Tsai, and C. Y. Chen, 2017: Data assimilation of ground-based GPS and radio occultation total electron content for global ionospheric specification. J. Geophys. Res., 122, 10876-10886, doi: 10.1002/2017JA024185. [Link]

Lin, C.-Y., C. C.-H. Lin, J.-Y. Liu, P. K. Rajesh, T. Matsuo, M.-Y. Chou, H.-F. Tsai, and W.-H. Yeh, 2020a: The early results and validation of FORMOSAT-7/COSMIC-2 space weather products: Global ionospheric specification and Ne-aided Abel electron density profile. J. Geophys. Res., 125, e2020JA028028, doi: 10.1029/2020JA028028. [Link]

Lin, J. T., C. H. Lin, L. C. Chang, H. H. Huang, J. Y. Liu, A. B. Chen, C. H. Chen, and C. H. Liu, 2012: Observational evidence of ionospheric migrating tide modification during the 2009 stratospheric sudden warming. Geophys. Res. Lett., 39, L02101, doi: 10.1029/2011GL050248. [Link]

Lin, J. T., C. H. Lin, P. K. Rajesh, J. Yue, C. Y. Lin, and T. Matsuo, 2020b: Local-time and vertical characteristics of quasi-6-day oscillation in the ionosphere during the 2019 Antarctic sudden stratospheric warming. Geophys. Res. Lett., 47, e2020GL090345, doi: 10.1029/2020GL090345. [Link]

Matsuo, T., I.-T. Lee, and J. L. Anderson, 2013: Thermospheric mass density specification using an ensemble Kalman filter. J. Geophys. Res., 118, 1339-1350, doi: 10.1002/jgra.50162. [Link]

Pedatella, N. M. and A. Maute, 2015: Impact of the semidiurnal lunar tide on the midlatitude thermospheric wind and ionosphere during sudden stratosphere warmings. J. Geophys. Res., 120, 10740-10753, doi: 10.1002/2015JA021986. [Link]

Pedatella, N. M., J. M. Forbes, A. Maute, A. D. Richmond, T. -W. Fang, K. M. Larson, and G. Millward, 2011: Longitudinal variations in the $F$ region ionosphere and the topside ionosphere-plasmasphere: Observations and model simulations. J. Geophys. Res., 116, A12309, doi: 10.1029/2011JA016600. [Link]

Pedatella, N.M., H.-L. Liu, F. Sassi, J. Lei, J.L. Chau, and X. Zhang, 2014: Ionosphere variability during the 2009 SSW: Influence of the lunar semidiurnal tide and mechanisms producing electron density variability. J. Geophys. Res., 119, 3828-3843, doi:

\subsection{2/2014JA019849. [Link]}

Pedatella, N. M., X. Yue, and W. S. Schreiner, 2015: Comparison between GPS radio occultation electron densities and in situ satellite observations. Radio Sci., 50, 518-525, doi: 10.1002/2015RS005677. [Link]

Qian, L., A. G. Burns, S. C. Solomon, and W. Wang, 2013: Annual/semiannual variation of the ionosphere. Geophys. Res. Lett., 40, 1928-1933, doi: 10.1002/ grl.50448. [Link]

Rajesh, P. K., C. H. Lin, C. Y. Lin, C. H. Chen, J. Y. Liu, T. Matsuo, S. P. Chen, W. H. Yeh, and C. Y. Huang, 2021: Extreme positive ionosphere storm triggered by a minor magnetic storm in deep solar minimum revealed by FORMOSAT-7/COSMIC-2 and GNSS observations. J. Geophys. Res., 126, e2020JA028261, doi: 10.1029/2020JA028261. [Link]

Rishbeth, H., I. C. F. Müller-Wodarg, L. Zou, T. J. FullerRowell, G. H. Millward, R. J. Moffett, D. W. Idenden, and A. D. Aylward, 2000: Annual and semiannual variations in the ionospheric F2-layer: II. Physical discussion. Ann. Geophys., 18, 945-956, doi: 10.1007/ s00585-000-0945-6. [Link]

Scherliess, L., D. C. Thompson, and R. W. Schunk, 2009: Ionospheric dynamics and drivers obtained from a physics-based data assimilation model. Radio Sci., 44, RS0A32, doi: 10.1029/2008RS004068. [Link]

Schreiner, W. S., S. V. Sokolovskiy, C. Rocken, and D. C. Hunt, 1999: Analysis and validation of GPS/MET radio occultation data in the ionosphere. Radio Sci., 34, 949-966, doi: 10.1029/1999RS900034. [Link]

Schreiner, W. S., C. Rocken, S. Sokolovskiy, S. Syndergaard, and D. Hunt, 2007: Estimates of the precision of GPS radio occultations from the COSMIC/FORMOSAT-3 mission. Geophys. Res. Lett., 34, L04808, doi: 10.1029/2006GL027557. [Link]

Schreiner, W. S., J. P. Weiss, R. A. Anthes, J. Braun, V. Chu, J. Fong, D. Hunt, Y.-H. Kuo, T. Meehan, W. Serafino, J. Sjoberg, S. Sokolovskiy, E. Talaat, T. K. Wee, and Z. Zeng, 2020: COSMIC-2 radio occultation constellation: First results. Geophys. Res. Lett., 47, e2019GL086841, doi: 10.1029/2019GL086841. [Link]

Sun, Y.-Y., J.-Y. Liu, H.-F. Tsai, and A. Krankowski, 2017: Global ionosphere map constructed by using total electron content from ground-based GNSS receiver and FORMOSAT-3/COSMIC GPS occultation experiment. GPS Solut., 21, 1583-1591, doi: 10.1007/ s10291-017-0635-4. [Link]

Syndergaard, S., D. C. Hunt, W. S. Schreiner, and C. Rocken, 2004: In situ electron density in low earth orbit from radio occultation data. Abstract SF52A-08, AGU Fall Meeting 2004, American Geophysical Union, San Francisco, CA, US.

Syndergaard, S., W. S. Schreiner, C. Rocken, D. C. Hunt, and K. F. Dymond, 2006: Preparing for COSMIC: 
Inversion and analysis of ionospheric data products. In: Foelsche, U., G. Kirchengast, and A. Steiner (Eds.), Atmosphere and Climate: Studies by Occultation Methods, Springer, Berlin, Heidelberg, 137-146, doi: 10.1007/3-540-34121-8_12. [Link]

Tien, J. Y., B. B. Okihiro, S. X. Esterhuizen, G. W. Franklin, T. K. Meehan, T. N. Munson, D. E. Robison, D. Turbiner, and L. E. Young, 2012: Next generation scalable spaceborne GNSS science receiver. Proceedings of the 2012 International Technical Meeting of The Institute of Navigation, Newport Beach, CA, 882-914.

Tulasi Ram, S., S.-Y. Su, and C. H. Liu, 2009: FORMOSAT-3/COSMIC observations of seasonal and longitudinal variations of equatorial ionization anomaly and its interhemispheric asymmetry during the solar minimum period. J. Geophys. Res., 114, A06311, doi: 10.1029/2008JA013880. [Link]

Wu, D. L., 2020: Ionospheric S4 Scintillations from GNSS Radio Occultation (RO) at Slant Path. Remote Sens., 12, 2373, doi: 10.3390/rs12152373. [Link]

Wu, Q., W. S. Schreiner, S.-P. Ho, H.-L. Liu, and L. Qian, 2017: Observations and simulations of eddy diffusion and tidal effects on the semiannual oscillation in the ionosphere. J. Geophys. Res., 122, 10502-10510, doi: 10.1002/2017JA024341. [Link]

Wu, Q., N. M. Pedatella, J. J. Braun, W. S. Schreiner, J. Weiss, M. Y. Chou, I. Zakharenkova, I. Cherniak, D. Hunt, R. A. Heelis, and T. Vanhove, 2022: Comparisons of Total Ion Density Derived from IVM and GNSS TEC on the FORMOSAT-7/COSMIC-2 Mission. Manuscript submitted for publication.

Yue, X., W.S. Schreiner, J. Lei, S. V. Sokolovskiy, C. Rock- en, D.C. Hunt, and Y.-H. Kuo, 2010: Error analysis of Abel retrieved electron density profiles from radio occultation measurements. Ann. Geophys., 28, 217-222, doi: 10.5194/angeo-28-217-2010. [Link]

Yue, X., W. S. Schreiner, C. Rocken, and Y.-H. Kuo, 2011: Evaluation of the orbit altitude electron density estimation and its effect on the Abel inversion from radio occultation measurements. Radio Sci., 46, RS1013, doi: 10.1029/2010RS004514. [Link]

Yue, X., W. S. Schreiner, Y.-H. Kuo, D. C. Hunt, W. Wang, S. C. Solomon, A. G. Burns, D. Bilitza, J.-Y. Liu, W. Wan, and J. Wickert, 2012: Global 3-D ionospheric electron density reanalysis based on multisource data assimilation. J. Geophys. Res., 117, A09325, doi: 10.1029/2012JA017968. [Link]

Zakharenkova, I. E., A. Krankowski, I. I. Shagimuratov, Y. V. Cherniak, A. Krypiak-Gregorczyk, P. Wielgosz, and A. F. Lagovsky, 2012: Observation of the ionospheric storm of October 11, 2008 using FORMOSAT-3/COSMIC data. Earth Planets Space, 64, 505512, doi: 10.5047/eps.2011.06.046. [Link]

Zakharenkova, I. E., I. Cherniak, and I. Shagimuratov, 2017: Observations of the Weddell Sea Anomaly in the ground-based and space-borne TEC measurements. $J$. Atmos. Sol.-Terr. Phys., 161, 105-117, doi: 10.1016/j. jastp.2017.06.014. [Link]

Zeng, Z., A. Burns, W. Wang, J. Lei, S. Solomon, S. Syndergaard, L. Qian, and Y.-H. Kuo, 2008: Ionospheric annual asymmetry observed by the COSMIC radio occultation measurements and simulated by the TIEGCM. J. Geophys. Res., 113, A07305, doi: 10.1029/2007JA012897. [Link] 